\title{
Micro Composite Multi Structural Formable Steel: Optimization of Electrodeposition Parameters and Anti- corrosion Properties of Polypyrrole Coatings
}

\author{
Ahmed Hefnawy 1,2,*iD, Dina Mostafa ${ }^{2}$ (D), Shaker Ebrahim ${ }^{2}$, Moataz Soliman 2 (D) \\ 1 Department of Chemistry, College of Science, University of Bahrain, Sakhir 32038, Bahrain; ahefnawy@uob.edu.bh \\ (A.H.); \\ 2 Department of Materials Science, Institute of Graduate Studies \& Research, Alexandria University, P.O. Box 832, Egypt; \\ ahmed.hefnawy@alexu.edu.eg (A.H.); \\ * Correspondence: ahmed.hefnawy@alexu.edu.eg, ahefnawy@uob.edu.bh (A.H.);
}

Scopus Author ID 16174905600

Received: 10.01.2021; Revised: 5.02.2021; Accepted: 7.02.2021; Published: 13.02.2021

\begin{abstract}
Polypyrrole (PPy) doped with 2-acrylamido-2-methyl-1-propanesulfonic acid sodium salt (AMPSNa) coating was electrochemically deposited MMFX steel by chronopotentiometry technique. The effect of concentration of AMPSNa, the applied current density, and deposition time on corrosion protection efficiency were investigated. The corrosion protection ability of the PPy/AMPSNa coating was studied using polarization curves and electrochemical impedance spectroscopy (EIS) after the electrodes had been immersed in a $0.6 \mathrm{M} \mathrm{NaCl}$ solution. PPy films were characterized by infrared spectroscopy and scanning electron microscopy. The results showed that PPy /AMPSNa coating has a cauliflower-like nodular surface and a uniformly thin layer covering the surface. With electrochemically deposition condition $0.03 \mathrm{M}$ AMPSNa, $2 \mathrm{~mA} / \mathrm{cm}^{2}$ for $7.5 \mathrm{~min}$. the PPy coatings tended to exhibit better corrosion protection ability.
\end{abstract}

Keywords: polypyrrole film; MMFX steel; corrosion; electrochemical deposition; EIS.

(C) 2021 by the authors. This article is an open-access article distributed under the terms and conditions of the Creative Commons Attribution (CC BY) license (https://creativecommons.org/licenses/by/4.0/).

\section{Introduction}

Protection of alloys by using conductive polymers had attracted many researchers in the past years who have studied the protective effect of various chemically or electrochemically synthesized conductive polymers on metal surfaces [1-7]. The corrosion protection mechanism of these metals and alloys by using the conducting polymers includes forming a protective barrier layer. The efficiency of these protective coatings, which provide thin, tough, and durable barriers to the metal substrate, depends on many factors like the suitability of organic materials, deposition techniques, and corrosive environment [8]. These conductive coatings can be electropolymerized directly onto the metal substrates. Electropolymerization has the advantage of being a one-step method, time-saving, good adhesion, and controllable process than chemical polymerization [9]. Polypyrrole has many applications such as chemical sensors, rechargeable batteries, supercapacitors, and corrosion inhibitors [10, 11]. It has been elucidated polypyrrole's adherent films to increase the passive region's steel potential to provide anodic protection. Electropolymerization of pyrrole on steel surface competes with the dissolution of iron. Therefore the selection of a suitable supporting electrolyte is an important factor [12, 13]. AMPSNa has a sulfonic acid group, and it is suitable to be considered a supporting electrolyte 
for PPy deposition. Ebrahim et al. [13] reported the electrochemical synthesis of PPy doped AMPSNa using the chronoamperometric technique. However, they used platinum electrode as a substrate. In the present work, we focused on optimizing the deposition parameters such as doping concentration, current density, and a deposition time of PPy film as corrosion protective coating for MMFX steel. PPy doped with AMPSNa coatings are deposited by using chronopotentiommetry technique. The corrosion current density, corrosion potential and inhibition efficiency, charge transfer resistance are calculated from potentiodynamic polarization and EIS curves.

\section{Materials and Method}

\subsection{Materials.}

Micro Composite Multi Structural Formable Steel (MMFX) using as a substrate with an elemental composition of $0.11 \%(\mathrm{C}), 0.18 \%(\mathrm{Si}), 0.5 \%(\mathrm{Mn}), 0.001 \%$ ( P) , $0.01 \%(\mathrm{~S})$, $8.72 \%(\mathrm{Cr}), 0.11 \%(\mathrm{Ni}), 0.03 \%(\mathrm{~V}), 0.16 \%(\mathrm{Cu})$ and $90.1 \%(\mathrm{Fe})$. Pyrrole monomer was purchased from Sigma-Aldrich, and it was stored in a dark area before the experiment. AMPSNa was obtained from Merck, and it is also used without further purification as a supporting electrolyte. Acetone and $\mathrm{NaCl}$ were purchased from Aldrich. All solutions were prepared in deionized water.

\subsection{Electrodeposition of PPy.}

MMFX steel electrode was firstly cleaned mechanically by using emery papers with different grit sizes (600(coarse), 800, 1000, and 1200 (fine)), followed by washing with distilled water and then with acetone in an ultrasonic bath to remove any oil or grease on the steel surface. This substrate was embedded in resin with an exposed area of $2.01 \mathrm{~cm}^{2}$, and it is used as a working electrode. A glass sealed platinum coil, and a saturated calomel electrode (SCE) were used as counter and reference electrodes, respectively. Electropolymerization and corrosion experiments were carried out in a three-electrode electrochemical cell. PPy film was prepared from aqueous solutions of pyrrole and AMPSNa onto MMFX steel using the chronopotentiometry technique. All electrochemical deposition techniques were carried out using Gamry (Potentiostats/Galvanostat/G750) with pilot integration controlled by PHE200 software.

\subsection{Potentiodynamic and EIS Measurements.}

The corrosion resistance of samples in a $0.6 \mathrm{M} \mathrm{NaCl}$ solution, before and after the surface treatment, was estimated using electrochemical methods ( potentiodynamic polarization curves and electrochemical impedance spectroscopy ) GAMRY PCI4G750 instrument $[14,15]$.

The scanned potential was performed from an initial potential of $-0.8 \mathrm{~V}$ vs. SCE to a final potential of $-0.2 \mathrm{~V}$ vs. SCE with a scan rate of $1 \mathrm{mV} / \mathrm{s}$ and step size $2 \mathrm{mV}$. The electrochemical polarization behavior of MMFX steel was investigated in $0.6 \mathrm{M} \mathrm{NaCl}$ solution at room temperature at different concentrations of AMPSNa, current densities, and deposition times, respectively. EIS was performed in $0.6 \mathrm{M} \mathrm{NaCl}$ within the frequency range from 100 $\mathrm{kHz}$ to $1 \mathrm{mHz}$ at 10 points per decade with an $\mathrm{AC}$ voltage amplitude of $10 \mathrm{mV}$ at the same conditions. 


\subsection{Surface Characterization.}

Fourier transformer infrared (FTIR) spectrum of PPy film was obtained by using Perkin Elmer spectrophotometer (Spectrum Bx) in a spectral region range $\left(4400 \mathrm{~cm}^{-1}\right.$ to $\left.350 \mathrm{~cm}^{-1}\right)$. The AMPSNa doped PPy coated steel electrode morphology was investigated using SEM (JEOL JSM 5300) with an acceleration voltage of $25 \mathrm{kV}$.

\section{Results and Discussion}

\subsection{Electrodeposition of PPy Doped with AMPSNa.}

PPy films doped with AMPSNa are electrodeposited onto the MMFX steel electrode in the galvanostatic mode. The galvanostatic mode has an advantage that the operator, which can prevent the cell and the potentiostat from sudden overloading [16], can easily determine the AC and DC levels. The concentration of AMPSNa dopant applied current density, and deposition time are the three main parameters needed to be studied to achieve the optimum conditions of preparation of PPy film on steel.

3.1.1. Electrodeposition of PPy coating at different concentrations of AMPSNa and corrosion behavior of MMFX steel.

Initially, PPy films were deposited onto MMFX steel electrode using chronopotentiometry technique from a solution of $0.1 \mathrm{M}$ pyrrole and different concentrations of AMPSNa with a deposition time of 7.5 min current density of $4 \mathrm{~mA} / \mathrm{cm}^{2}$ as shown in Figure1.

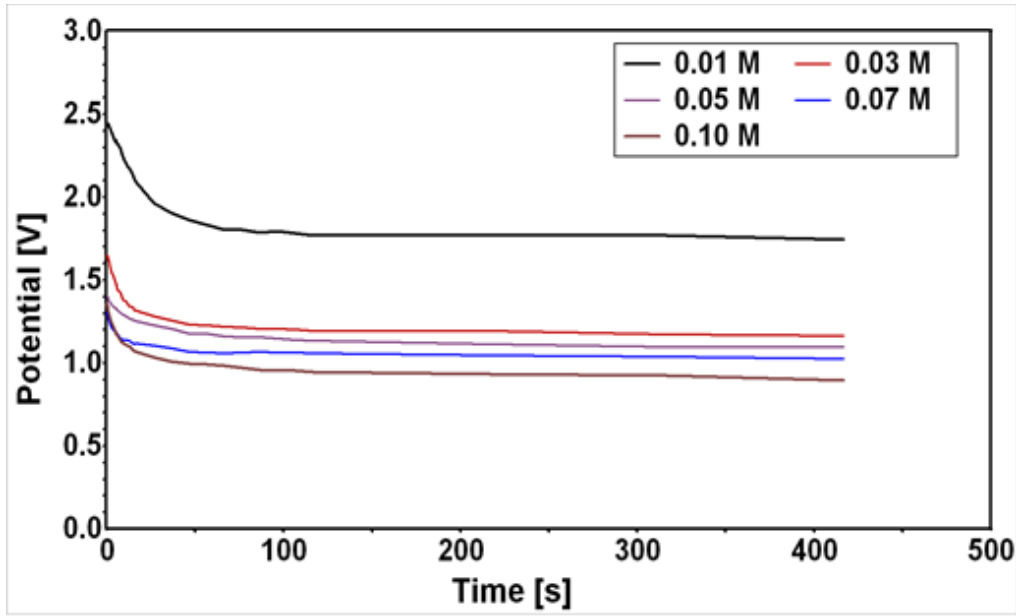

Figure 1. Chronopotentiometry curves of MMFX steel electrodeposited with PPy doped with AMPSNa from different concentrations of AMPSNa at a current density of $4 \mathrm{~mA} / \mathrm{cm}^{2}$ for $7.5 \mathrm{~min}$.

It is observed that the PPy started to grow at the edge of the electrode, which acts as a specific geometric for nucleation centers. Due to the small number of nucleation centers at the beginning of the experiment (mostly edges of the electrode), the polymerization potential decreased to low potential. At this potential, other nucleation centers are created in the other parts of the steel electrode. As a result, there is a subsequent drop of potential at a certain point, and finally, the potential is stabilized. This result indicates that the whole steel electrode is coated by PPy film. The PPy is continued to homogeneously grow onto the whole steel electrode surface [17]. It is observed that the increase of the AMPSNa concentration reduces the potential needed for the polymerization. Also, at a low concentration of $0.01 \mathrm{M}$ AMPSNa, the polymerization potential is higher than $1.5 \mathrm{~V} / \mathrm{SCE}$, leading to over oxidation, degradation, 
and undesirable side reaction. These results are matching the one obtained by Patois et al. [17] where pyrrole was electropolymerized at different potentials: $0.7 \mathrm{~V} / \mathrm{SCE}$ and 1.0 V/SCE that was inferior to the oxidation potential of the pyrrole monomers; but $1.3 \mathrm{~V} / \mathrm{SCE}$ and $1.7 \mathrm{~V} / \mathrm{SCE}$ that were superior to the oxidation potential of pyrrole. It is necessary to mention that PPy films, which consist of neutral and oxidized pyrrole units, are electro synthesized at low positive potential $(<1.1 \mathrm{~V} / \mathrm{SCE}=$ oxidation potential of pyrrole $)$ over oxidized PPy films are electro synthesized at much higher positive potentials. This over oxidation results in the addition of carbonyl group $\mathrm{C}=\mathrm{O}$ to the polymer chain, which reduces the film's conductivity.

Figure 2 shows the potentiodynamic polarization studies of MMFX steel coated with PPy film doped with different concentrations of AMPSNa, and it has emerged in a corrosive solution of $0.6 \mathrm{M} \mathrm{NaCl}$. From these results, Tafel extrapolations show that the MMFX steel coated with PPy doped with AMPSNa shifts the corrosion potential positively. This may be due to the stored charge (polarons and bipolarons) in the PPy films. In addition, from the data analysis of Figure 2, it is observed that the corrosion current density (icorr) values for coated steel by PPy prepared with a different concentration range of AMPSNa $\left(1.79 \mu \mathrm{A} / \mathrm{cm}^{2}-8.84\right.$ $\left.\mu \mathrm{A} / \mathrm{cm}^{2}\right)$ are smaller than those of uncoated steel $(175.1 \mu \mathrm{A} / \mathrm{cm} 2)$. Consequently, it minimizes the corrosion rate when the MMFX steel is coated with PPy/AMPSNa. This is maybe because of the formation of a less porous and dense film. Su and Iroh reported a less porous and denser PPy film structure when the electrolyte's dopant concentration was extremely low.

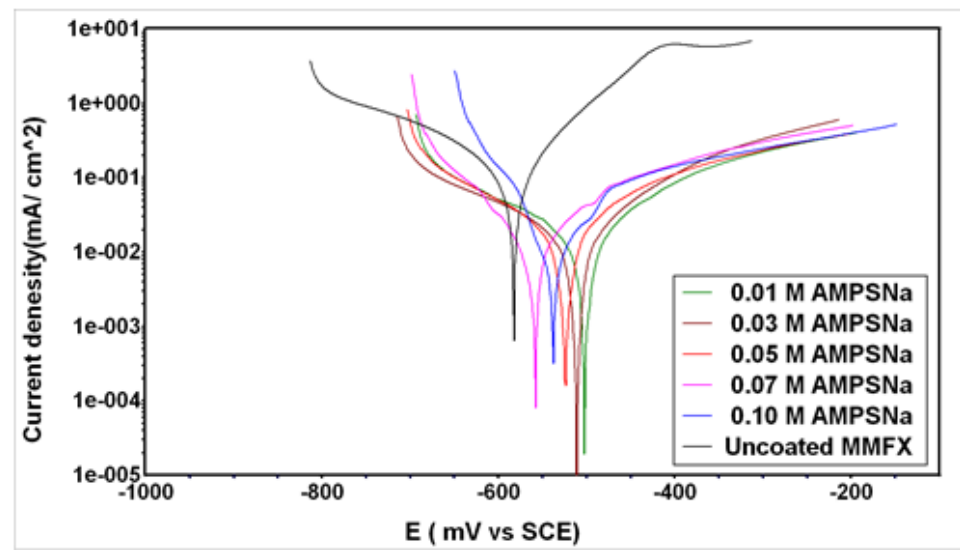

Figure 2. Potentiodynamic curves of uncoated MMFX steel electrode and MMFX steel electrodeposited with PPy doped with different concentrations of AMPSNa by using chronopotentiometry at a current density of $4 \mathrm{~mA} / \mathrm{cm}^{2}$ for deposition time of $7.5 \mathrm{~min}$.

It is found that at a low concentration of AMPSNa $(0.01 \mathrm{M}$ and $0.03 \mathrm{M})$, the icorr values are $1.79 \mu \mathrm{Acm}-2$ and $0.22 \mu \mathrm{Acm}^{-2}$, respectively. By calculating the protection efficiency $(\mu \mathrm{P})$ of PPy/AMPSNa film on MMFX steel, it is equal to $99.85 \%$ at $0.03 \mathrm{M}$ AMPSNa. Consequently, it can be concluded that the optimum concentration of AMPSNa is $0.03 \mathrm{M}$. EIS measurements were performed for samples coated with and without PPy film doped with different concentrations of AMPSNa and emerged in a corrosive solution of $0.6 \mathrm{M} \mathrm{NaCl}$. The Bode plot has some distinct features over the Nyquist plot. Since frequency seems to be one of the axes, it is handy to understand how the impedance counts on the frequency. Figure 3 displays Bode plots, in which the impedance modulus is plotted versus frequency on a logarithmic scale. It reveals that MMFX steel samples coated with PPy/AMPSNa films have higher impedance value $\left(64.28 \Omega \mathrm{cm}^{2}\right)$ are obtained when the concentration of AMPSNa is $0.01 \mathrm{M}$ and $0.03 \mathrm{M}$. By calculating the protection efficiency ( $\mu \mathrm{EIS})$, it is $92 \%$. 


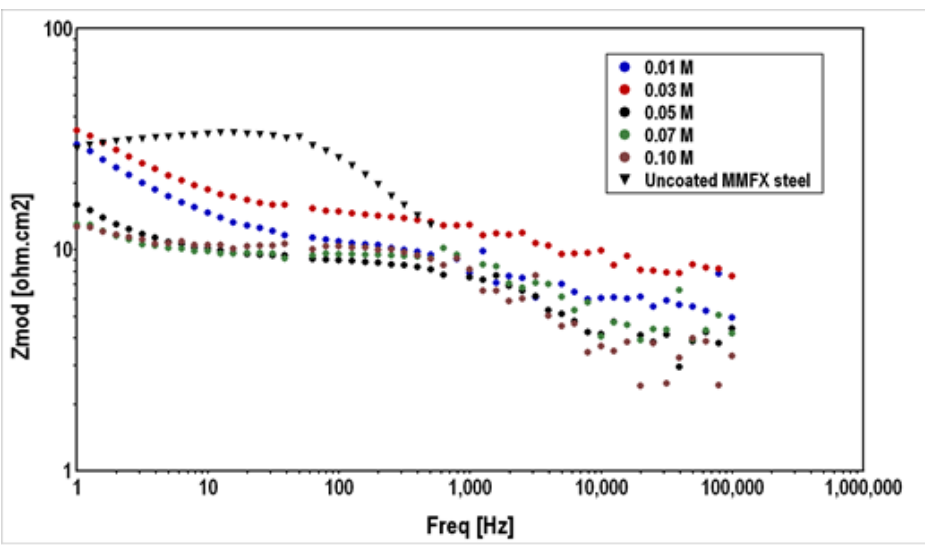

Figure 3. Bode plot of uncoated MMFX steel electrode and MMFX steel electrodeposited with PPy doped with different concentrations of AMPSNa at a current density of $4 \mathrm{~mA} / \mathrm{cm}^{2}$ for a deposition time of $7.5 \mathrm{~min}$.

3.1.2. Electrodeposition of PPy coating at different current densities and corrosion behavior of MMFX steel.

The effect of different current densities on the electrodeposition of PPy doped with 0.03 M AMPSNa for 7.5 min deposition time was investigated, as shown in Figure 4. It is observed that the increase of the current density enhances the measured polymerization potential, which may lead to over oxidation for PPy [17]. For current densities higher than $2 \mathrm{~mA} . \mathrm{cm}^{-2}$, the potential rises instantaneously to high positive values. Then, it begins to decrease slowly to a potential value that is more positive than $0.8 \mathrm{~V}$ because the current densities are higher than 2 $\mathrm{mA} / \mathrm{cm}^{2}$. Besides the PPy electrodeposition, the over oxidation process of the polymeric chain might occur [18].

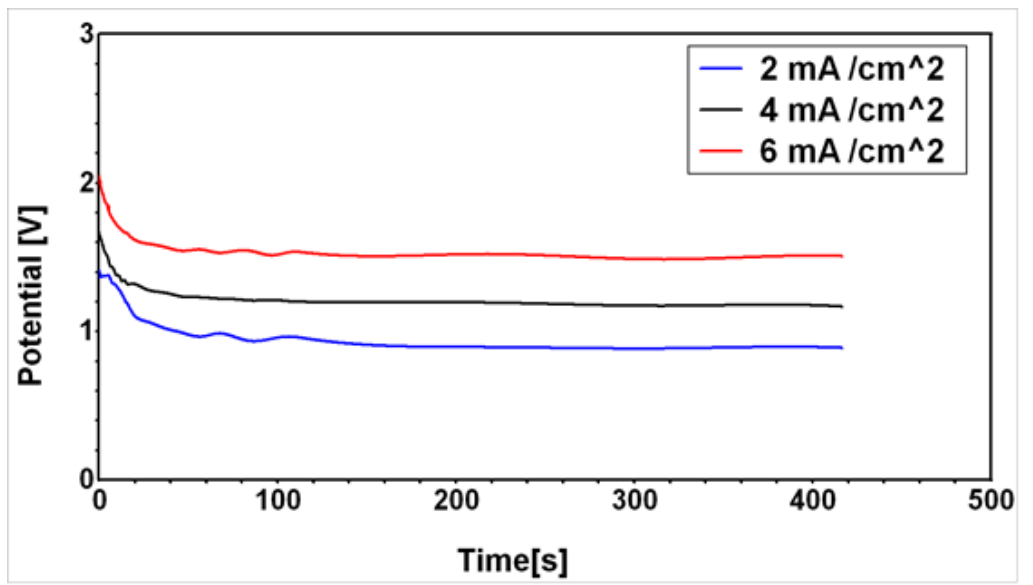

Figure 4. Chronopotentiometry curves of MMFX steel electrodeposited with PPy doped with $0.03 \mathrm{M}$ of AMPSNa at different current densities for $7.5 \mathrm{~min}$.

Figure 5 shows the potentiodynamic polarization curves of MMFX steel uncoated and coated with PPy/AMPSNa films exposed to $0.6 \mathrm{M} \mathrm{NaCl}$ solution at different applied current densities 2, 4, and $6 \mathrm{~mA} \cdot \mathrm{cm}^{-2}$. By analyzing the polarization curves using the traditional Tafel method. The icorr obtained is $175.1 \mu \mathrm{A} / \mathrm{cm}^{2}$ for the uncoated MMFX steel, and 0.128, 0.294, $1.44 \mu \mathrm{A} / \mathrm{cm} 2$ for the coated sample at applied current densities $2,4,6 \mathrm{~mA} / \mathrm{cm}^{2}$, respectively. It is clear the applied current density decreased the icorr is constringed, and the protection efficiency super fat. This is due to the high electropolymerization potential, which leads to the over oxidation of PPy at high current density. This results in a short-chain length leading to the formation of defects along the chain forming a less protective film [19]. Therefore, the optimum polymerization current density is $2 \mathrm{~mA} / \mathrm{cm} 2$ with a protection efficiency of $99.92 \%$. The data 
presented in Figure 6 shows that the shape of the impedance spectra of MMFX steel coated with PPy film doped with $0.03 \mathrm{M}$ of AMPSNa, with deposition time 7.5 minutes in $0.6 \mathrm{M} \mathrm{NaCl}$ solution at different applied current densities $\left(2,4\right.$, and $\left.6 \mathrm{~mA} / \mathrm{cm}^{2}\right)$. It is observed that the impedance increases as the applied current densities decreases, and hence the protection efficiency promotes to rich to $94.47 \%$ at applied current densities $2 \mathrm{~mA} / \mathrm{cm}^{2}$.

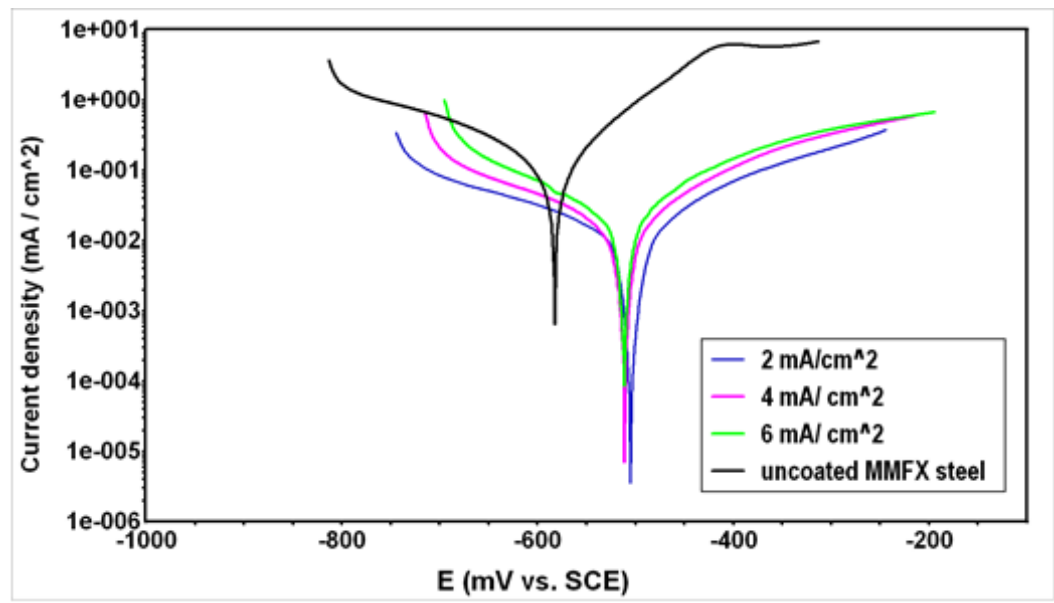

Figure 5. Potentiodynamic curves of uncoated MMFX steel electrode and MMFX steel electrodeposited with PPy doped with $0.03 \mathrm{M}$ AMPSNa by using chronopotentiometry at different current densities for a deposition time of $7.5 \mathrm{~min}$.

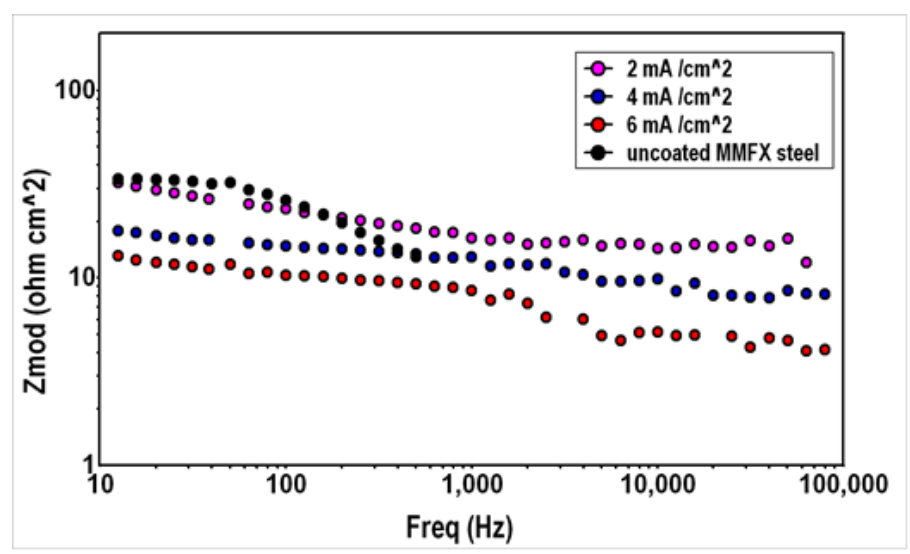

Figure 6. Bode plot of uncoated MMFX steel electrode and MMFX steel electrodeposited with PPy doped with $0.03 \mathrm{M}$ of AMPSNa by at different current densities for a deposition time of $7.5 \mathrm{~min}$.

3.1.3. Electrodeposition of PPy coating at different deposition times and corrosion behavior of MMFX steel.

Different deposition times have been used to study their effects on the thickness and homogeneity of PPy films' electrodeposition formed onto MMFX steel, as shown in Figure 7. It is observed that in a low deposition time of $5 \mathrm{~min}$, the electropolymerization period is not enough to produce the effective PPy film. Also, it is observed that the increase in the deposition time leads to an increase in the film thickness.

The extracted data from polarization curves Figure 8 for the range of deposition time $(5,7.5,10,15$, and $30 \mathrm{~min}$.), offering the values of icorr in those times $(0.56,0.17,0.42,0.81$, $63.2 \mu \mathrm{A} / \mathrm{cm} 2$ respectively). So the minimum value of icorr is $0.17 \mu \mathrm{A} / \mathrm{cm}^{2}$, it is equivalent to $99.87 \%$ corrosion protection efficiency is obtained when deposition times equal to 7.5 minutes. This may be due to the increase in deposition time leading to degradation of the film obtained, 
which allows the penetration of chloride ions (aggressive species) to metal surface leading to the corrosion process.

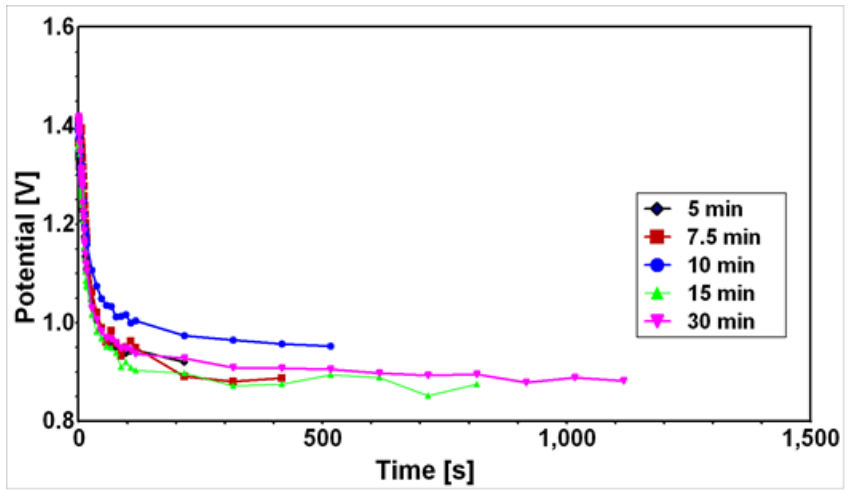

Figure 7. Chronopotentiometry curves of MMFX steel electrodeposited with PPY doped with $0.03 \mathrm{M}$ of AMPSNa at a current density of $2 \mathrm{~mA} / \mathrm{cm}^{2}$ for different deposition times.

The measured Bode plots of MMFX steel uncoated and coated with PPy/ AMPSNa films exposed to $0.6 \mathrm{M} \mathrm{NaCl}$ solution at different deposition times are shown in Figure 9. According to the measured Bode plots, an increasing value of impedance is associated with decreased deposition time up to 7.5 minutes. Further, a decrease in deposition time leads to a decrease in impedance and, hence, decreases in the corrosion protection efficiency. The greatest corrosion protection efficiency is obtained at the time of deposition of $7.5 \mathrm{~min}$.

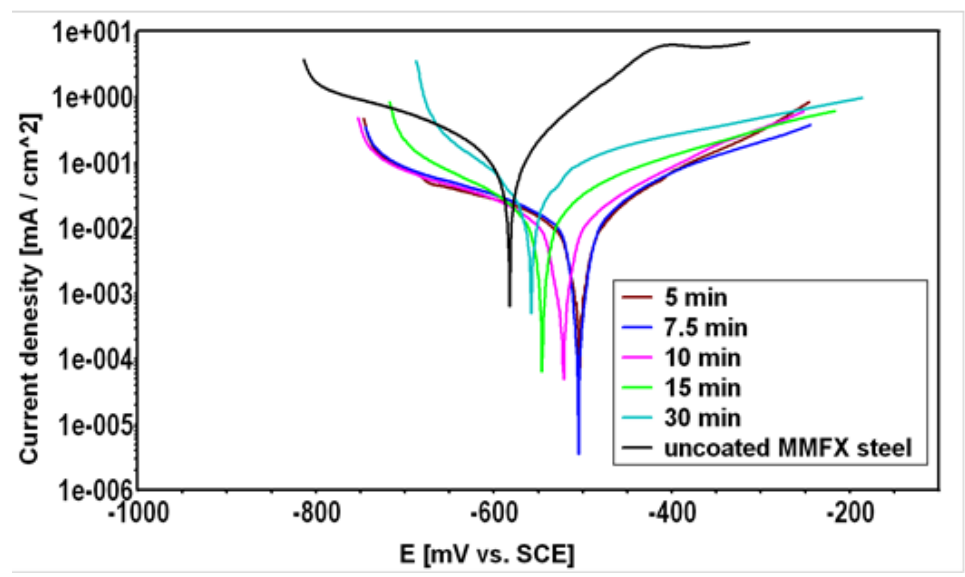

Figure 8. Potentiodynamic curves of uncoated MMFX steel electrode and MMFX steel electrodeposited with PPy doped with $0.03 \mathrm{M}$ AMPSNa using chronopotentiometry at a current density of $2 \mathrm{~mA} / \mathrm{cm}^{2}$ for different deposition times.

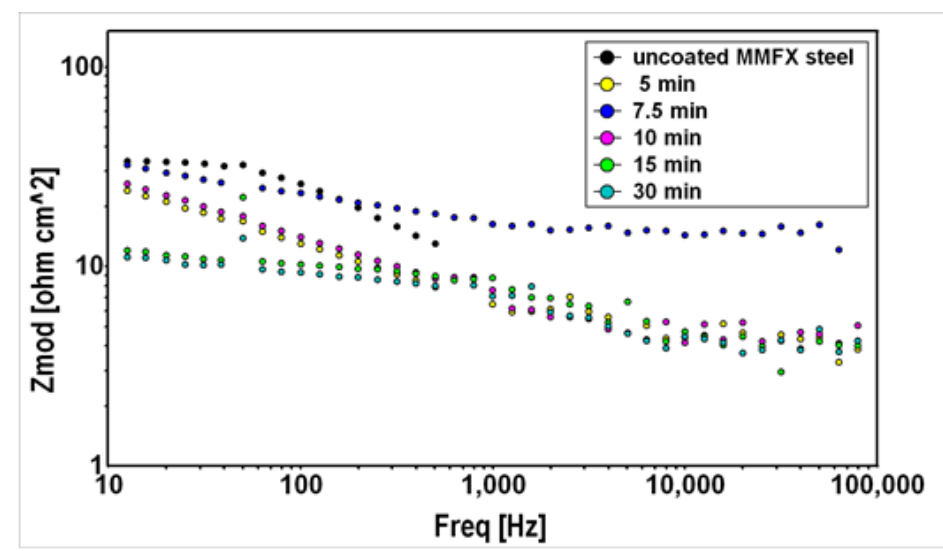

Figure 9. Bode plot of uncoated MMFX steel electrode and MMFX steel electrodeposited with PPy doped with $0.03 \mathrm{M}$ of AMPSNa at $2 \mathrm{~mA} / \mathrm{cm}^{2}$ for different deposition times. 


\subsection{Structural and Morphological Properties of PPy Films Doped with AMPSNa.}

FTIR spectroscopy was used to study PPY films' structural doped with AMPSNa, as shown in Figure 10. AMPSNa doped PPy film was electrodeposited using a $0.1 \mathrm{M}$ pyrrole solution and a $0.03 \mathrm{M}$ AMPSNa using the chronopotentiometry technique. The peak at $662 \mathrm{~cm}^{-}$ ${ }^{1}$ is attributed to C-C out of plane deformation of the ring [20]. The peak at $942 \mathrm{~cm}^{-1}$ is due to $\mathrm{C}-\mathrm{H}$ out of plane deformation [21]. The weak band at $1052 \mathrm{~cm}^{-1}$ is due to $\mathrm{C}-\mathrm{H}$ out of plane bending vibration. The band corresponding to the $\mathrm{C}-\mathrm{H}$ bending appears at $1228 \mathrm{~cm}-1$ [21]. The two bands at $1520 \mathrm{~cm}^{-1}$ and $1426 \mathrm{~cm}^{-1}$ are attributed to the benzenoid ring's $\mathrm{C}=\mathrm{C}$ stretching mode. The peak at $1656 \mathrm{~cm}^{-1}$ is due to the $\mathrm{C}=\mathrm{C}$ of the quinoid ring. The band near $2968 \mathrm{~cm}^{-1}$ attributed to $\mathrm{C}-\mathrm{H}$ stretching vibrations in AMPSNa [22]. The peak at $3508 \mathrm{~cm}^{-1}$ is assigned to $\mathrm{N}-\mathrm{H}$ stretching vibration [23]. To investigate the morphology of the AMPSNa doped PPy coatings, SEM was performed on MMFX steel coated with PPy doped with AMPSNa.

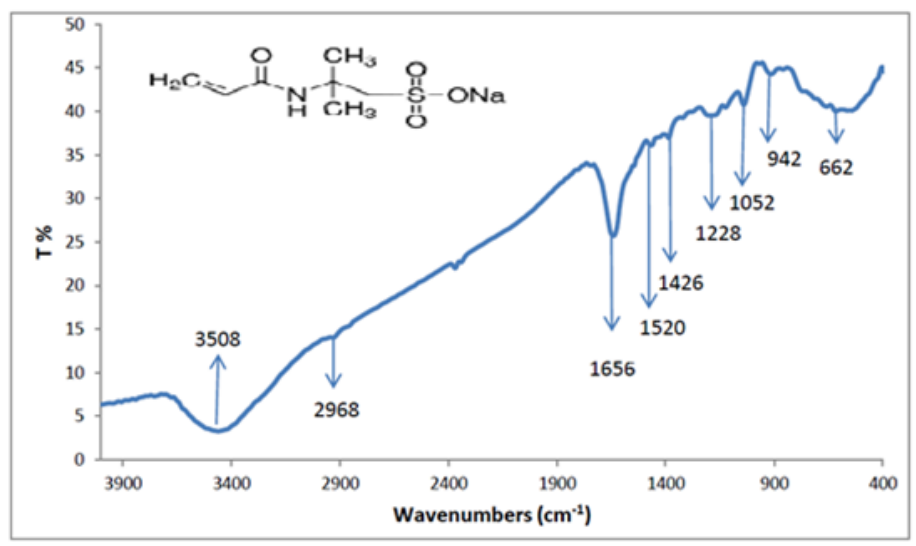

Figure 10. FTIR spectrum of PPy doped with AMPSNa.
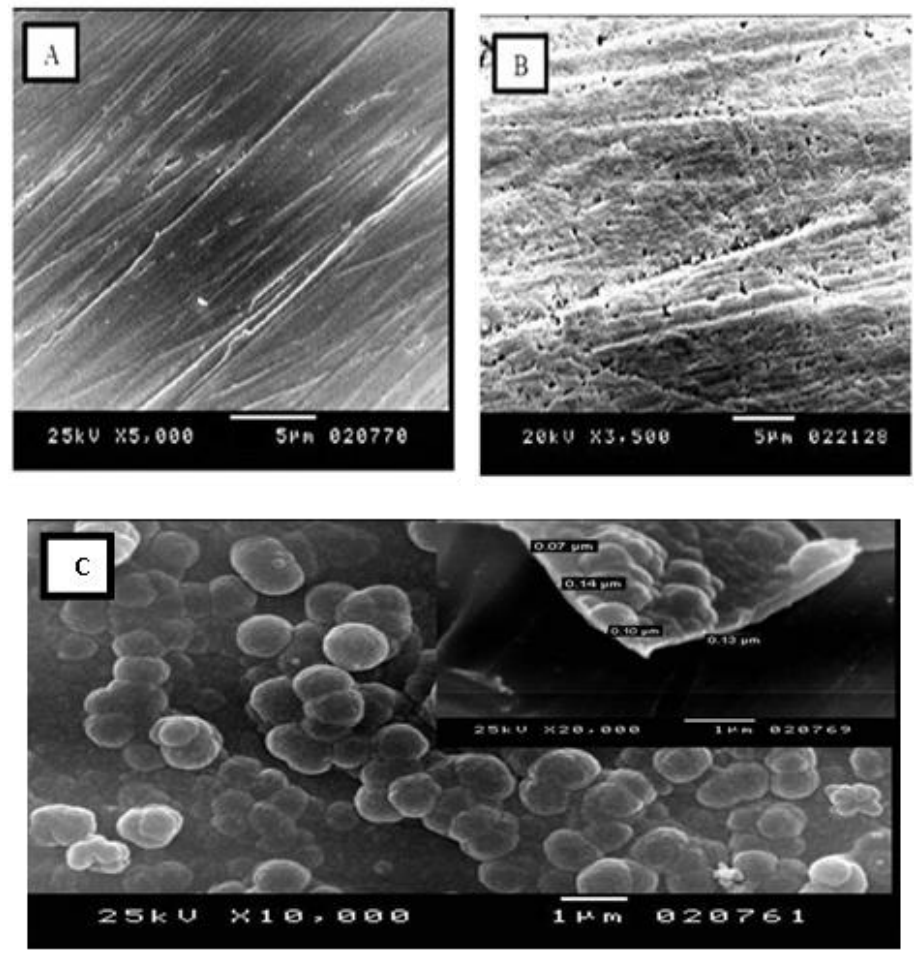

Figure 11. SEM photographs of MMFX steel electrodeposited with PPy doped with AMPSNa by using chronopotentiometry technique compared with (A) freshly polished MMFX steel electrode; (B) the electrode after immersion in $0.6 \mathrm{M} \mathrm{NaCl} ;(\mathbf{C})$ the electrode coated with PPy doped with AMPSNa at the optimum current density of $2 \mathrm{~mA} / \mathrm{cm}^{2}$ and a deposition time of $7.5 \mathrm{~min}$. 
Figure 11A shows the MMFX steel surface's SEM image before immersion in the solution of $0.6 \mathrm{M} \mathrm{NaCl}$. It can be seen that the surface of the steel is affected by the abrasive finishing process. The surface morphology of MMFX steel immersed in $0.6 \mathrm{M} \mathrm{NaCl}$ and PPy films' absence is illustrated in Figure 11B. The surface is strongly corroded by the medium, resulting in a corrosion layer covering most of the surface. A relatively porous and pitting layer was formed. SEM micrographs of MMFX steel electrodeposited with PPY doped with $0.03 \mathrm{M}$ of AMPSNa by imposing a current density of $2 \mathrm{~mA} \cdot \mathrm{cm}^{-2}$ for 7.5 minutes are shown in Figure (11C). It is observed that PPy films are uniformly covering MMFX steel's surface with spherical and small particles size of the average diameter of $1 \mu \mathrm{m}$. Furthermore, the films have a cauliflower-like nodular surface morphology without any defects. The deposited films are thin, with an average thickness of $0.14 \mu \mathrm{m}$.

\section{Conclusions}

In conclusion, the coating of PPy with AMPSNa as a new dopant was generated through an electrodeposition approach on MMFX steel's surface to inhibit corrosion. This coating showed adequate corrosion protection in $\mathrm{NaCl}$ through a mechanism of a protective barrier formation. The optimum PPy films deposited from $0.1 \mathrm{M}$ pyrrole doped with $0.03 \mathrm{M}$ AMPSNa by using chronopotentiometry technique at a current density of $2 \mathrm{~mA} / \mathrm{cm}^{2}$ and a deposition time of $7.5 \mathrm{~min}$ have demonstrated the best electrochemical response with a protection efficiency of $99.9 \%$.

\section{Funding}

This research received no external funding.

\section{Acknowledgments}

This research has no acknowledgments.

\section{Conflicts of Interest}

The authors declare no conflict of interest.

\section{References}

1. Bazli, L.; Yusuf, M.; Farahani, A.; Kiamarzi, M.; Seyedhosseini, Z.; Nezhadmansari, M.; Aliasghari, M.; Iranpoor, M. Application of composite conducting polymers for improving the corrosion behavior of various substrates: A Review. Journal of Composites and Compounds 2020, 2, https://doi.org/10.29252/jcc.2.4.7.

2. Adhikari, A.; De, S.; Rana, D.; Nath, J.; Ghosh, D.; Dutta, K.; Chakraborty, S.; Chattopadhyay, S.; Chakraborty, M.; Chattopadhyay, D. Selective sensing of dopamine by sodium cholate tailored polypyrrolesilver nanocomposite. Synth. Met. 2020, 260, 116296, https://doi.org/10.1016/j.synthmet.2020.116296.

3. Wang, C.; Sun, X.; Yang, L.; Song, D.; Wu, Y.; Ohsaka, T.; Matsumoto, F.; Wu, J. In Situ Ion-Conducting Protective Layer Strategy to Stable Lithium Metal Anode for All-Solid-State Sulfide-Based Lithium Metal Batteries. Advanced Materials Interfaces 2021, 8, 2001698, https://doi.org/10.1002/admi.202001698.

4. Yin, X.; Mu, P.; Wang, Q.; Li, J. Superhydrophobic ZIF-8-Based Dual-Layer Coating for Enhanced Corrosion Protection of Mg Alloy. ACS Applied Materials \& Interfaces 2020, 12, 35453-35463, https://doi.org/10.1021/acsami.0c09497.

5. Situ, Y.; Ji, W.; Liu, C.; Xu, J.; Huang, H. Synergistic effect of homogeneously dispersed PANI-TiN nanocomposites towards long-term anticorrosive performance of epoxy coatings. Prog. Org. Coat. 2019, 130, 158-167, https://doi.org/10.1016/j.porgcoat.2019.01.034. 
6. Jlassi, K.; Radwan, A.B.; Sadasivuni, K.K.; Mrlik, M.; Abdullah, A.M.; Chehimi, M.M.; Krupa, I. Anticorrosive and oil sensitive coatings based on epoxy/polyaniline/magnetite-clay composites through diazonium interfacial chemistry. Sci. Rep. 2018, 8, 13369, https://doi.org/10.1038/s41598-018-31508-0.

7. Rui, M.; Zhu, A. The synthesis and corrosion protection mechanisms of PANI/CNT nanocomposite doped with organic phosphoric acid. Prog. Org. Coat. 2021, 153, 106134, https://doi.org/10.1016/j.porgcoat.2021.106134.

8. Li, J.; He, Y.; Sun, Y.; Zhang, X.; Shi, W.; Ge, D. Synthesis of Polypyrrole/V2O5 Composite Film on the Surface of Magnesium Using a Mild Vapor Phase Polymerization (VPP) Method for Corrosion Resistance. Coatings 2020, 10, https://doi.org/10.3390/coatings10040402.

9. Ates, M. A review on conducting polymer coatings for corrosion protection. J. Adhes. Sci. Technol. 2016, 30, 1510-1536, https://doi.org/10.1080/01694243.2016.1150662.

10. Ates, B.; Koytepe, S.; Ulu, A.; Gurses, C.; Thakur, V.K. Chemistry, Structures, and Advanced Applications of Nanocomposites from Biorenewable Resources. Chem. Rev. 2020, 120, 9304-9362, https://doi.org/10.1021/acs.chemrev.9b00553.

11. Zielińska, D.; Rydzkowski, T.; Thakur, V.K.; Borysiak, S. Enzymatic engineering of nanometric cellulose for sustainable polypropylene nanocomposites. Industrial Crops and Products 2021, 161, 113188, https://doi.org/10.1016/j.indcrop.2020.113188.

12. Maw, S.; Smela, E.; Yoshida, K.; Stein, R.B. Effects of monomer and electrolyte concentrations on actuation of PPy(DBS) bilayers. Synth. Met. 2005, 155, 18-26, https://doi.org/10.1016/j.synthmet.2005.05.017.

13. Ebrahim, S.M.; Latif, M.M.A.-E.; Gad, A.M.; Soliman, M.M. Cyclic voltammetry and impedance studies of electrodeposited polypyrrole nanoparticles doped with 2-acrylamido-2-methyl-1-propanesulfonic acid sodium salt. Thin Solid Films 2010, 518, 4100-4105, https://doi.org/10.1016/j.tsf.2009.10.167.

14. Abbas, R.; Elkhoshkhany, N.; Hefnawy, A.; Ebrahim, S.; Rahal, A. High Stability Performance of Superhydrophobic Modified Fluorinated Graphene Films on Copper Alloy Substrates. Advances in Materials Science and Engineering 2017, 2017, 6197872, https://doi.org/10.1155/2017/6197872.

15. Fetouh, H.A.; Hefnawy, A.; Attia, A.M.; Ali, E. Facile and low-cost green synthesis of eco-friendly chitosansilver nanocomposite as novel and promising corrosion inhibitor for mild steel in chilled water circuits. $J$. Mol. Liq. 2020, 319, 114355, https://doi.org/10.1016/j.molliq.2020.114355.

16. Lo, M.; Ktari, N.; Gningue-Sall, D.; Madani, A.; Aaron, S.E.; Aaron, J.-J.; Mekhalif, Z.; Delhalle, J.; Chehimi, M.M. Polypyrrole: a reactive and functional conductive polymer for the selective electrochemical detection of heavy metals in water. Emergent Materials 2020, 3, 815-839, https://doi.org/10.1007/s42247020-00119-9.

17. Patois, T.; Lakard, B.; Monney, S.; Roizard, X.; Fievet, P. Characterization of the surface properties of polypyrrole films: Influence of electrodeposition parameters. Synth. Met. 2011, 161, 2498-2505, https://doi.org/10.1016/j.synthmet.2011.10.003.

18. Ashassi-Sorkhabi, H.; Kazempour, A. Incorporation of organic/inorganic materials into polypyrrole matrix to reinforce its anticorrosive properties for the protection of steel alloys: A review. J. Mol. Liq. 2020, 309, 113085, https://doi.org/10.1016/j.molliq.2020.113085.

19. García Rueda, F.C.; González, J.T. Electrochemical polymerization of polypyrrole coatings on hard-anodized coatings of the aluminum alloy 2024-T3. Electrochim. Acta 2020, 347, 136272, https://doi.org/10.1016/j.electacta.2020.136272.

20. Sarıarslan, H.; Karaca, E.; Şahin, M.; Pekmez, N.Ö. Electrochemical synthesis and corrosion protection of poly(3-aminophenylboronic acid-co-pyrrole) on mild steel. RSC Advances 2020, 10, 38548-38560, https://doi.org/10.1039/D0RA07311C.

21. Diauudin, F.N.; Mohd Noor, S.A.; Abdul Rashid, J.I.; Feizal Knight, V.; Wan Yunus, W.M.Z.; Ong, K.K.; Mohd Kasim, N.A.; Taufik, S.; Samsuri, A.; Shamsudin, I.J.; Latip, W. Preparation and Characterisation of Polypyrrole-Iron Oxyhydroxide Nanocomposite as Sensing Material. Advances in Materials Science and Engineering 2020, 2020, 8762969, https://doi.org/10.1155/2020/8762969.

22. Bhalerao, A.B.; Bulakhe, R.N.; Deshmukh, P.R.; Shim, J.-J.; Nandurkar, K.N.; Wagh, B.G.; Vattikuti, S.V.P.; Lokhande, C.D. Chemically synthesized 3D nanostructured polypyrrole electrode for high performance supercapacitor applications. Journal of Materials Science: Materials in Electronics 2018, 29, 15699-15707, https://doi.org/10.1007/s10854-018-9175-0.

23. Alghamdi, A.A.; Al-Odayni, A.-B.; Saeed, W.S.; Al-Kahtani, A.; Alharthi, F.A.; Aouak, T. Efficient Adsorption of Lead (II) from Aqueous Phase Solutions Using Polypyrrole-Based Activated Carbon. Materials 2019, 12, https://doi.org/10.3390/ma12122020. 